\title{
Toward Building a Culture of Strengths in U.S. MSW Programs
}

\author{
Linda Plitt Donaldson \\ Barbara P. Early \\ Min-Ling Wang
}

\begin{abstract}
Social work has embraced the strengths perspective as a vital part of micro, mezzo, and macro practice. Yet the authors' experience suggests that the medical model of deficits, disease, and disorder remains the dominant paradigm. This exploratory study sought to determine how and to what extent strengths-based practice is integrated into the MSW practice curriculum. Forty-four (44) of 181 programs responded to a 12-item web-based survey. Quantitative and qualitative responses indicate an almost universal awareness of and attention to integrating strengths-based content. However, a smaller number of programs appear to be looking beyond curriculum content towards the creation of a broader culture of strengths. Even so, challenges remain toward overcoming a pathological orientation in social work practice curricula.
\end{abstract}

Keywords: Social work education, strengths, assets, social work practice, culture of strengths

\section{INTRODUCTION}

Since the publication of Saleebey's first edition of The Strengths Perspective in Social Work Practice (1992), the social work profession has embraced the strengths perspective as a vital part of the foundation of practice at the micro, mezzo, and macro levels. The Council on Social Work Education (CSWE) defines the purpose of social work practice as the promotion of “. . . Human well-being by strengthening opportunities, resources, and capacities of people in their environments and by creating policies and services to correct conditions that limit human rights and the quality of life" (CSWE, 2001, p. 2) Further, CSWE requires curriculum content on practice at both the BSW and MSW levels to be focused on “. . . Strengths, capacities, and resources of client systems in relation to their broader environments” (p. 10).

However, in the practice experience of the authors and in their students' reports from the field, the medical model of deficit, disease, and disorder remains present if not the dominant model of social work practice in all, not just health-related, settings. In addition, less than half of our field agencies report using a "theory base" that includes a focus on strengths and empowerment. For those that do, they typically identify strengthsbased methods as one in a long list of models they use that could be applied from a strengths-perspective or not. While agency policy and individual social workers use the language of strengths, there is a parallel and competing focus on pathology and problems. True strengths-based practice requires that “. . . Everything you do as a social worker will be predicated, in some way, on helping to discover and embellish, explore and exploit clients' strengths and resources in the service of assisting them to achieve their goals,

\footnotetext{
Linda Plitt Donaldson, Ph.D., is an assistant professor, Barbara P. Early, Ph.D., is an associate professor and Min-Ling

Wang is a doctoral candidate, all in the National Catholic School of Social Service at the Catholic University of America in Washington, DC.
}

Copyright (c) 2009 Advances in Social Work Vol. 10 No. 2 (Fall 2009), 211-229 
realize their dreams, and shed the irons of their own inhibitions and misgivings, and society's domination” (Saleebey, 2006, p. 1).

Educators are challenged to prepare students for strengths-based practice in a society and professional discipline that remain primarily problem-centered and deficit-focused. In such a context, a mere integration of strengths-based content into the curriculum may not be sufficient to educate, socialize, and help students internalize strengths as a paradigm, perspective, or set of practice models. MSW programs may need to create a culture of strengths where strengths-based practice is taught in the curriculum, modeled by faculty in faculty-student interactions, and integrated in other aspects of the program. An organizational culture refers to shared values, assumptions, beliefs, norms, and expectations that guide the thoughts, feelings, and actions of organizational participants in all areas of their work (Hemelgarn, Glisson \& James, 2006). In MSW programs, organizational participants primarily include faculty, administrators, staff, and students. Creating a culture of strengths may represent the stronger commitment required by MSW programs to deliver social work education that best prepares students for strengthsoriented practice in a problem-centered world.

This paper reports the findings of a preliminary study of Master of Social Work (MSW) programs in the United States. The study sought to determine how and to what extent strengths-based practice is integrated into the practice curriculum and educational climate of MSW programs as a beginning look for a culture of strengths. This paper first discusses the struggle the profession has endured in its attempt to shift from a disease model to one of strength followed by a discussion of organizational culture and how that may be applied to conceptualize a culture of strengths within an MSW program. To present the study, the paper describes the methodology and preliminary findings, and concludes with the implications of those findings for social work education and research.

For the purpose of this study and consistent with the literature on strengths-based practice, we define strengths-based social work practice (Saleebey, 2006) as micro, mezzo, and macro methods that facilitate change by first placing an emphasis on uncovering the strengths, capacities, resources and assets of individuals, family, and/or community and building upon those strengths, etc., to promote change. Examples of strengths-based methods include: solution-focused and narrative therapies (DeJong \& Berg, 2002; Freedman \& Combs, 1996); strengths-based case management (Rapp, 1998); asset-based community development (Kretzman \& McKnight, 1993); and popular education (Friere, 1993). We view the teaching of strengths-based practice methods as guided by the following underlying principles:

- All individuals and families have strengths and all environments have resources;

- Growth and change happen by mobilizing strengths to further develop and capitalize on existing resources rather than placing a primary focus on deficits, disease, dysfunction, or disorder.

- The role of a practitioner is non-expert. It is collaborative, educative, and facilitative; the individual, family, and/or community are experts on themselves. 


\section{LITERATURE REVIEW}

In 1915 Abraham Flexner argued that social work was not a profession, in part, because it lacked a systematic and transmissible set of practice methods and a grounding in science (2001). The budding profession responded to this critique by developing a culture and set of practice methods where "treatment" for the ills of individuals and society was predicated on presenting problems and deficits, modeled after the medical profession. Specht and Courtney (1994) chronicle the profession's "connection with modern psychiatry in the 1920s, psychoanalysis in the 1930s, and humanistic psychology in the 1950s" (p. 97) leading to its emphasis on fixing the problems within the individual. Modern day social work visionaries believed that the traditional disease model of explaining social and psychological problems and the medical model of intervention or treatment were not reflective of core social work values. Therefore, they began to propose another way to view helping.

Among those visionaries was Ann Weick, who in 1983 wrote a seminal article on this emerging perspective entitled "Issues in Overturning a Medical Model of Social Work Practice.” In it, she called for a "health-oriented paradigm of human behavior" (p. 467) in which clients no longer "give over" the assigning of meaning of their "illness" to an expert, but rather mobilize their capacity for self-healing. However, even the "health" model, while changing the locus of healing from the expert to the self, continued to imply an "illness" to be healed. As time progressed, the health paradigm transformed into the strengths perspective, again with Weick and others (1989) shifting the dynamic from healing to change or growth and eschewing the need for diagnosis as a prerequisite for that change. The emerging strengths perspective is captured in the posing of a question, "The question is not what kind of a life one has had, but what kind of a life one wants, and then bring to bear all the personal and social resources available to accomplish this goal” (p. 353).

In both articles, Weick and her colleagues gave examples of the conflict between social work's deeply held values and the intransigent culture of the medical model. They noted that in the medical model a problem must be named and its cause determined by an expert. In this process a client is required to give over control of the understanding of the problem to the meaning system of the healer. This presents a conflict with the espoused social work values of inherent dignity of the person, and self determination and empowerment in change. If social work assessment and intervention were based instead on an inherent belief in human potential, the conflict would be ameliorated.

The new paradigm of strength more firmly grounded itself into social work practice in the 1980s. The deinstitutionalization of persons with serious and persistent mental illness via the 1963 Mental Retardation Facilities and Community Mental Health Centers Construction Act led to the need for more effective community-based methods to serve people with the most severe forms of mental illness in their transition from hospital to community (Solomon, 1992). In 1982, representatives of the University of Kansas School of Social Welfare developed the first of a series of case management pilot projects that led to the development of strengths-based case management (Staudt, Howard \& Drake, 2001). In addition, the Great Society programs established through the Economic 
Opportunity Act of 1964, particularly the community action agencies, led to a resurgence of community and policy practice models whose principles could be summarized by the phrase "power to the people" (Fisher, 2005, p.47), practice principles that align well with strengths-based practice methods. Since then, a growing practice literature has developed in micro, mezzo, and macro practice (Berg, 1994; Butler, 2005; Chapin, 1995; DeJong \& Miller, 1995; Green, McAllister \& Tarte, 2004; Rapp, 1998; Rapp \& Lane, 2009; Waites, 2009).

In addition, social work education has embraced the strengths perspective. The Council on Social Work Education mandates strengths content in its Educational Policy and Accreditation Standards (CSWE, 2001). Many contemporary texts are oriented towards strength and capacity, in the generalist (DuBois \& Miley, 2005; Poulin, 2004; Timberlake, Farber \& Sabatino, 2008), clinical (DeJong \& Berg, 2002; Helton \& Smith, 2004; Rapp \& Goscha, 2006), and macro (Chapin, 2007; Long, Tice \& Morrison, 2005) practice areas. However, it is not clear that the profession is ready to break out of its emphasis on disease and disorder to fully embrace and internalize the mobilization of strengths as the core focal point for interventions.

Social work education is designed to socialize and educate competent social work professionals, to generate knowledge, and to exercise leadership in the profession. Consequently, to prepare students to competently apply knowledge and skills in strengths-based practice, schools of social work must both teach a strengths-based curriculum and model a culture of strength within their organizations or programs. This study is an effort to begin assessing the extent to which MSW programs in the United States integrate strengths-based content into their programs. To determine whether an existing study on social work education and strengths-based practice had previously been done, the researchers queried databases in the scholarly literature (social work abstracts, social services abstracts, and sociological abstracts) using key word searches that paired the term "social work education" or "education" with the following terms: strengths, resilience, assets, empowerment, coping, capacity, and resources. Researchers also reviewed the table of contents for the previous ten years of the Journal of Social Work Education and the Journal of Teaching in Social Work. None of these efforts uncovered any study examining the state of strengths-based practice in U.S. MSW programs.

\section{Organizational Culture}

Organizational culture refers to the shared norms, beliefs and behavioral expectations that drive behavior and communicate what is valued in an organization (Hemelgarn, Glisson \& James, 2006). Schein (2004) describes culture as a gestalt, where the whole is more than the sum of its parts. Some of the elements that comprise this culture gestalt include, e.g., shared language, norms, values, roles, formal philosophies, habits of thinking, and formal rituals. However, while these elements are a manifestation of culture, they do not capture the full essence of culture, for they do not address the depth and breadth of those manifestations, nor do they let the observer fully understand how these elements integrate to create the gestalt. Schein proposes three levels of culture to define, describe, and understand the various dimensions of culture within an organization. 
Schein (2004) refers to Level 1, where the surface level of culture exists, as Artifacts. These are "the phenomena that one sees, hears, and feels when" they encounter an organization (p. 25). Examples of the artifacts include language used, visible products such as mission and value statements, formal descriptions of organization, and so on. Schein notes the importance of realizing that these artifacts are easy to observe but very difficult to interpret unless one was part of the culture that created these artifacts or has used these artifacts for some time, i.e., taking an anthropological approach. Level 2 refers to Espoused Values and Beliefs. Schein differentiates between actual values and beliefs and "espoused" values and beliefs. Espoused values and beliefs are those which a group aspires to reflect in their actions and behaviors, but have not yet achieved. Schein refers to Level 3, as Underlying Assumptions, which are views about the organization, its structure and processes, ways of being that are a given. They are so ingrained as part of the culture, they are unconscious to the stakeholders and taken-for-granted as "the way it is." These underlying assumptions often begin as espoused values and beliefs, but overtime become fully internalized and second-nature to organizational or group members.

Social work researchers have acknowledged the need for change in the organizational culture of social work programs when a curricular change represents a challenge to traditional assumptions, values, and attitudes of program faculty. Nichols-Casebolt, Figueira-McDonough and Netting (2000) argue for social work curricula that integrate the long-neglected experiences of women throughout the curricula, including a critical analysis of how women's experiences have informed the dominant theories and models that form the basis for social work knowledge construction and intervention. Because this curricular shift reflects "a major shift in institutional culture whereby fundamental beliefs [are] challenged” (p. 67), the authors recommend that the change strategy begin by assessing the school's culture. Nichols-Casebolt et al. argue that an understanding of culture is important to achieve desired changes in program curricula, but they do not explicitly address the changes, beyond the program curricula, that would represent a cultural shift beyond curricular issues. Several authors have talked about the importance of changing the professional culture of social work programs to promote the teaching of evidence-based practice (EBP) (Shlonsky \& Stern, 2007; Soydan, 2007; Springer, 2007). Springer observes that this shift in culture requires more than an integration of EBP throughout the curriculum, but a modeling of critical inquiry in the classroom. This study begins to uncover cultural shifts some programs have embarked upon to both integrate and model strengths-based practice in their programs.

\section{METHODS}

This research project used a survey design to explore the degree to which U.S. MSW programs were integrating strengths-based content into their curricula. To gain a better sense of the strengths-based nature of the program, we solicited information on other indicators which may suggest that a program goes beyond curricular content in an effort to build a culture of strengths in the program. The researchers collected data through a web-based survey consisting of open-ended and closed-response questions sent to 181 chairs of accredited MSW Programs across the United States. Institutions were only 
permitted to submit one survey. The researchers selected a survey design for this initial inquiry into the integration of strengths into MSW programs, intending to follow-up with a set of the respondents with more in-depth qualitative interviews as a continuation of this project.

\section{Instrument}

The researchers developed a 12-item survey that was divided into two sections: 1 ) demographic information, and 2) strengths-based culture. A copy of the survey is included in the Appendix. The demographic information section solicited data about the respondents (i.e., their position and number of years they had been with the program), and the program itself (i.e., the number of full-time tenure-line faculty members; the number of part-time or non tenure-line faculty members, the number of students in the program, and a list of concentrations). The strengths-based culture section included six questions designed to assess the degree to which programs infused and promoted a culture of strengths.

Language is the primary symbolic representation through which groups, organizations, and communities convey their culture. Therefore, the first survey question related to strengths-based culture asked respondents to list the words used in their MSW programs' written materials that "indicate the presence of strengths-based social work practice content in your curriculum." In the second survey question, respondents were given a set of 10 characteristics (see Table 4), and were asked to select all items that applied to their program during the last academic year. To use Schein's (2004) terminology for culture, these 10 characteristics, along with the language programs use to convey strengths, represent the Level 1 dimension of a culture of strengths within an MSW program. These characteristics represent the artifacts, the visible manifestations and formal descriptions of the organization and do not necessarily reflect a deep or broad culture of strengths within the program.

Respondents were also asked to rank their programs on a scale from 1 to 10 according to 1) the extent to which the program infuses strengths-based content in the curriculum, and 2) how well the program promotes the learning of micro-mezzo-macro strengths-based practice methods. For these two scalar questions, respondents were asked to elaborate on why they selected the numerical ranking. The qualitative explanations of these rankings provided some insight into the degree to which a program's strengthsbased culture extended beyond artifacts to include Schein's Level 2, espoused values and beliefs, and Level 3, underlying assumptions or degree to which a strengths-based culture is internalized within MSW programs.

\section{Data Analysis}

The data analysis included both quantitative and qualitative methods. The quantitative data were coded and entered into SPSS. Researchers calculated average scores for the scalar question responses and ran correlations among various program characteristics to test for significance. In addition, researchers used SPSS to analyze descriptive features of the programs. Researchers entered the qualitative data into a Word 
document and analyzed those responses together as a team to assess convergence between quantitative and qualitative data. Researchers also analyzed the qualitative data to identify items beyond the 10 characteristics given in the instrument that demonstrate a strengths-based program, and to uncover challenges toward building a strengths-based culture in MSW programs. The results of the data analysis are presented below.

\section{RESULTS}

This section presents the findings from this exploratory research project. First, a profile of the respondents is presented. Next is a discussion of how programs create a culture of strengths, including the language used to connote strengths and the characteristics that reflected an integration of strengths into their programs, i.e., the artifacts (Schein, 2004) of a strengths-based culture. Included in this discussion are some of the challenges expressed by respondents in moving their program culture beyond mere artifacts to a level where a strengths-based culture is reflected in the values and beliefs of its members through their actions, behaviors, and ways of being, i.e., Levels 2 and 3 of

Schein's framework. A discussion with implications of these findings concludes the paper.

\section{Profile of Respondents}

Representatives of forty-four of the 181 programs (24.3\%) completed the survey. Table 1 includes a breakdown of demographic characteristics of the respondents and their programs. Of the 44 respondents, most were on the faculty either in MSW Department Chairs/Directors positions $(\mathrm{n}=18,40.9 \%)$ or in a regular tenure-line faculty position $(\mathrm{n}=13,30 \%)$. Most respondents had been with their program between 8 and 12 years $(n=14,31.8 \%)$, although 8 respondents had been with their programs 19 years or more.

The 44 programs were sorted into size categories based on the number of students. Twenty-six percent were considered small, $30 \%$, medium, and $44 \%$ were large. The majority of respondent programs (87\%) were located in places from the Midwest to the Northeast, with very few respondents in Western states. The majority of programs (59\%) were located on urban campuses. There were no significant relationships found between any of these demographic characteristics and strengths-based rankings. However, all four of the programs located on rural campuses were among the high and highest self-ranked programs regarding how well they infused and promoted strengths-based content. This causes one to ponder possible cultural differences between programs located in urban versus rural locations, a question that was beyond the scope of this study.

\section{Culture of Strengths in MSW Programs}

The Language of Strengths. Schein (2004) includes language as an important artifact of culture. Saleebey (2006) writes of a "lexicon of strengths" (p. 10), reminding the reader that words and language exert strong influence on practice and on the self assessment of clients. The words chosen by respondents to indicate the presence of strengths-based social work practice in their curricula reflect one type of artifact (Schein) showing how their culture of strengths are observable to outsiders. The respondents' 
words fell into four general types-two describing client characteristics and positive processes and two describing practitioner perspectives and methods.

Table 1: Demographics of MSW Program Respondents and Programs (N=44)

\begin{tabular}{lrr}
\hline Characteristic & N & $\mathbf{\%}$ \\
\hline Total Programs & 44 & 100 \\
Position of Respondents & & \\
Faculty & 13 & 30 \\
Department Chair/Director & 18 & 40 \\
Other & 13 & 30
\end{tabular}

Years have been with the program

$0-3$

$5 \quad 11$

4-7

$7 \quad 16$

$8-12$

$14 \quad 32$

$13-18$

$10 \quad 23$

$19-30$

Over 30

$6 \quad 14$

Program Size (\# of students)*

Small (0-100)

2

4

Medium (101-200)

1126

Large (Over 200)

$13 \quad 30$

Number of FT Tenure-line Faculty

$\begin{array}{lrr}4-7 & 12 & 27 \\ 8-12 & 19 & 43 \\ 13-18 & 5 & 11 \\ 19-30 & 8 & 19\end{array}$

Geographic Region

Northeast $\quad 9 \quad 20$

$\begin{array}{lll}\text { South } & 15 & 35\end{array}$

$\begin{array}{lll}\text { Midwest } & 14 & 32\end{array}$

$\begin{array}{lll}\text { West } & 5 & 11\end{array}$

$\begin{array}{lll}\text { Pacific } & 1 & 2\end{array}$

Campus Type

$\begin{array}{lll}\text { Urban } & 26 & 59\end{array}$

$\begin{array}{lll}\text { Suburban } & 14 & 32\end{array}$

\begin{tabular}{lrr} 
Rural & 4 & 9 \\
\hline
\end{tabular}

*Only 43 respondents indicated Program Size so percentages are calculated based on an $\mathrm{N}$ of 43. 
The first and largest category included individual client and external environmental characteristics. Within this category, there was considerable consistency of responses. For example, of individual characteristics, there were mentions of "strengths," or "ego strengths," "assets," "capacity” or "capability," "resilience,” and "resources.” Among the external or environmental characteristics, respondents mentioned "opportunity," "protective factors" and "risk and protective factors." The second category of responses described normative human growth process or positive goal oriented client behavior such as "coping," "growth," "post-traumatic growth,” and "rebound from adversity."

The third and fourth categories focused on the practitioner. The third reflected the practitioner's strengths-oriented view or perspective on clients. Examples were "strengths perspective," "strengths-based perspective," "biopsychosocial strengths-based perspective," and "strengths-based framework." The fourth and last category included the practice methods or approaches a strengths-oriented social worker might take. Words chosen included "assessment of assets and resources," "collaboration," "Freire model," "solution-focused," and "therapy for liberation, power and equality." One final contribution fit in none of the categories. It was simply, "Saleebey." Table 2 includes a full list of words mentioned by respondents placed into one of the four categories.

\section{Table 2: $\quad$ The Language of Strengths}

\begin{tabular}{|c|c|}
\hline Client/Person & Social Work Practitioner \\
\hline $\begin{array}{l}\text { Category 1: Client and Environment } \\
\text { Characteristics } \\
\text { Internal individual: strengths/ ego strengths } \\
(\mathrm{n}=13) \text {; assets (13); capacity (11); resilience } \\
\text { (17); resources (10); competency, human } \\
\text { capacity for growth, motivation, client } \\
\text { resourcefulness, human/social capital ( } \mathrm{n}=1 \text { ) } \\
\text { External environmental: resources (9); } \\
\text { opportunity, risk and protective factors, } \\
\text { supports, buffers ( } \mathrm{n}=1 \text { ) }\end{array}$ & $\begin{array}{l}\text { Category 3: Social Worker Perspective } \\
\text { Empowerment, empowerment oriented, } \\
\text { theories of empowerment (13); strengths, } \\
\text { strengths-based perspective, or } \\
\text { biopsychosocial strengths perspective (7), } \\
\text { holistic (3); strengths-based framework, } \\
\text { ecological framework, ecological and } \\
\text { strengths perspective, social and economic } \\
\text { justice, social work values and ethics, } \\
\text { partnership, respect ( } n=1)\end{array}$ \\
\hline $\begin{array}{l}\text { Category 2: Normative Human Growth } \\
\text { processes } \\
\text { Coping, growth, post traumatic growth, reach } \\
\text { potential, rebound from adversity, recovery, } \\
\text { skills (n=1) }\end{array}$ & $\begin{array}{l}\text { Category 4: Social worker practice methods } \\
\text { Strengths-based approach, practice, or models } \\
\text { (4); assessment of assets and resources, } \\
\text { strengths-based relationships, collaboration, } \\
\text { community collaboration, use of natural } \\
\text { networks, strengths-empowerment approach, } \\
\text { enhance client pride and competence, enhance } \\
\text { strengths, mobilizing supportive resources, } \\
\text { Freire model, advocacy, integrated practice, } \\
\text { therapy for liberation and power ( } \mathrm{n}=1)\end{array}$ \\
\hline
\end{tabular}


Self-Rankings for Infusing and Promoting Strengths. Respondents were asked to rank their programs according to two items: 1) the extent to which the program infuses strengths-based content in the curriculum (infusion), and 2) how well the program promotes the learning of micro-mezzo-macro strengths-based practice methods (promotion of practice). Table 3 shows how respondents ranked their programs on each item using a scale of 1 to 10 . As expected, since strengths content is required of MSW programs, only two respondents ranked their programs as very low (rankings of 1,2 or 3 ) for one or both questions. The majority of programs (34 out of 44) fell in the middle (scores of 4 through 9) with roughly 19\% giving themselves the highest ranking of 10 on one or both questions, indicating that strengths-based methods were extensively infused throughout their program and/or that their program promoted the learning of micromezzo-macro strengths-based methods extremely well.

Table 3: $\quad$ Self-Ranking Frequencies for Scalar Questions, Scale from 1 to 10 $(N=44)$

\begin{tabular}{|c|c|c|c|c|c|c|c|c|c|c|}
\hline & \multicolumn{10}{|c|}{ Self-Rankings } \\
\hline & \multicolumn{2}{|c|}{$1-3$} & \multicolumn{2}{|c|}{$4-6$} & \multicolumn{2}{|c|}{$7-9$} & \multicolumn{2}{|c|}{10} & \multicolumn{2}{|c|}{ Total } \\
\hline & $\underline{\mathrm{N}}$ & $\underline{\%}$ & $\underline{\mathrm{N}}$ & $\%$ & $\underline{\mathrm{N}}$ & $\underline{\%}$ & $\underline{\mathrm{N}}$ & $\underline{\%}$ & $\underline{\mathrm{N}}$ & $\underline{\%}$ \\
\hline $\begin{array}{l}\text { To what extent does your MSW } \\
\text { program infuse strengths-based } \\
\text { content throughout the } \\
\text { curriculum? }\end{array}$ & 2 & 4 & 15 & 34 & 19 & 43 & 8 & 19 & 44 & 100 \\
\hline $\begin{array}{l}\text { Overall, how well does your } \\
\text { MSW Program promote the } \\
\text { learning of micro-mezzo-macro } \\
\text { strengths-based practice } \\
\text { methods? }\end{array}$ & 1 & 2 & 11 & 25 & 23 & 53 & 9 & 20 & 44 & 100 \\
\hline
\end{tabular}

For each program, researchers took the average ranking from the two scalar items (infusion and promotion of practice), and categorized MSW programs according to the following criteria:

- Medium: Programs with average rankings between 2 and $6{ }^{1}$

- High: Programs with an average ranking of 6.5 to 9; and

- Highest: Programs with an average ranking of 10.

\footnotetext{
${ }^{1}$ The researchers placed two programs with average rankings of 6 into the High category because they selected 6 or more characteristics, and the qualitative responses to other survey items clearly demonstrated a culture of strengths consistent with other programs in the high category.
} 
Table 4 lists each strength characteristic and the corresponding number of respondents from the medium, high, and highest groups that indicated that their program reflects that characteristic. Again reflecting the CSWE mandate, nearly all programs $(n=42,95 \%)$ reported that they require texts or articles in foundation year courses that teach social work practice methods that use strengths or assets in the intervention (characteristic \#4). Furthermore, other characteristics selected by more than half of

Table 4: $\quad$ Comparing Selected Characteristics of Programs with Average SelfRankings of Medium, High, and Highest $(\mathrm{N}=44)$

\begin{tabular}{|c|c|c|c|c|c|c|c|c|}
\hline & \multicolumn{2}{|c|}{$\begin{array}{c}\text { Medium } \\
(1-6)\end{array}$} & \multicolumn{2}{|c|}{$\begin{array}{c}\text { High } \\
(6.5-9)\end{array}$} & \multicolumn{2}{|c|}{$\begin{array}{c}\text { Highest } \\
\text { (10) }\end{array}$} & \multicolumn{2}{|c|}{ Total } \\
\hline & $\underline{\mathrm{N}}$ & $\underline{\%}$ & $\underline{\mathrm{N}}$ & $\underline{\%}$ & $\underline{\mathrm{N}}$ & $\underline{\%}$ & $\underline{\mathrm{N}}$ & $\underline{\%}$ \\
\hline Total Programs by Ranking & 11 & 25 & 25 & 57 & 8 & 18 & 44 & 100 \\
\hline \multicolumn{9}{|l|}{ Characteristics } \\
\hline $\begin{array}{l}\text { 1. Explicitly refer to strengths/capacities/ } \\
\text { assets in program mission. }\end{array}$ & 2 & 18 & 16 & 64 & 7 & 88 & 25 & 57 \\
\hline $\begin{array}{l}\text { 2. Explicitly refer to strengths/capacities/ } \\
\text { assets in program goals. }\end{array}$ & 1 & 9 & 15 & 60 & 7 & 88 & 23 & 52 \\
\hline $\begin{array}{l}\text { 3. Explicitly refer to strengths/capacities/ } \\
\text { assets in program objectives. }\end{array}$ & 3 & 27 & 20 & 80 & 8 & 100 & 31 & 70 \\
\hline $\begin{array}{l}\text { 4. Require texts/articles in foundation year } \\
\text { courses that teach methods using } \\
\text { strengths and assets as part of the } \\
\text { intervention. }\end{array}$ & 10 & 91 & 24 & 96 & 8 & 100 & 42 & 95 \\
\hline $\begin{array}{l}\text { 5. Offer one or more advanced year } \\
\text { concentrations with strengths/assets as } \\
\text { the organizing principle, e.g., family } \\
\text { preservation. }\end{array}$ & 0 & 0 & 13 & 52 & 6 & 75 & 19 & 43 \\
\hline $\begin{array}{l}\text { 6. Introduce strengths-based concepts as } \\
\text { part of program orientation. }\end{array}$ & 3 & 27 & 17 & 68 & 7 & 88 & 27 & 61 \\
\hline $\begin{array}{l}\text { 7. Link students to field agencies whose } \\
\text { primary method of practice is strengths- } \\
\text { based. }\end{array}$ & 3 & 27 & 14 & 56 & 7 & 88 & 24 & 55 \\
\hline $\begin{array}{l}\text { 8. Offer faculty development workshops } \\
\text { to both PT and FT faculty on strengths- } \\
\text { based content. }\end{array}$ & 0 & 0 & 3 & 12 & 4 & 50 & 7 & 16 \\
\hline $\begin{array}{l}\text { 9. Offer continuing education in strengths- } \\
\text { based methods. }\end{array}$ & 1 & 9 & 7 & 28 & 1 & 13 & 9 & 21 \\
\hline $\begin{array}{l}\text { 10. Offer } 1 \text { or more discrete courses in } \\
\text { strengths-based approaches to social } \\
\text { work practice. }\end{array}$ & 0 & 0 & 4 & 16 & 2 & 25 & 6 & 14 \\
\hline
\end{tabular}


programs included: explicitly referring to strengths/capacities/assets in program mission, goals, and objectives (\#1, \#2, and \#3 respectively); introducing strengths-based concepts in program orientation (\#6); and linking students to field agencies whose primary method of practice is strengths-based (\#7).

Two of the least frequently selected characteristics across programs were \#8 and \#9; with less than $20 \%$ of programs offering faculty development or continuing education in strengths-based methods. This may be more a reflection of capacity or community priorities than a lack of program commitment to strengths. Notably, only six programs (14\%) indicated that they offer a discrete course in strengths-based methods such as Solution Focused Therapy, Asset Building, or Strengths-based Practice with Families. This may not reflect an inattention to strengths, as some programs use an integrated strategy to promote strengths rather than offering discrete courses.

Eight of the 44 respondents gave their programs the highest ranking, i.e., 10, on both infusing strengths-based content and promoting the learning of micro-mezzo-macro strengths-based practice methods. These eight highest ranking programs also tended to reflect an integration of strengths beyond the core curricula to include the program environment or culture. For example, several of them indicated that they introduce strengths concepts at program orientations, through faculty development workshops, and by linking students to field agencies with a primary practice model that emphasizes strengths. These highest ranking respondents deepened the meaning of their numerical self-rankings with qualitative comments that further explained the strengths-based nature of their program. Some respondents described strengths as the "core philosophy" or "organizing principle" underlying all aspects of their program. A respondent from a highest ranking program with 9 out of 10 characteristics reported that faculty research activities were "primarily strengths-oriented, with many consumers and family members involved in participatory action research.” Another respondent identified the writing and presentations of faculty as further evidence of commitment to strengths. One respondent reported that they not only infuse strengths throughout their curriculum and through characteristics 1 through 9, but also by reflecting a value and philosophy of strengths in their personal interactions with faculty, staff, and students, i.e., living their values and philosophy in each personal encounter.

It was difficult to characterize programs as "high" or "not-so-high," as "strong” or "not-so-strong" by the rankings chosen on infusion and promotion of strengths-based practice or by the number of strengths characteristics the chairs selected to describe their programs. In fact, there was sometimes a discrepancy between the strength of the ranking and the size of the number of characteristics chosen with some respondents ranking their programs as high yet selecting only four or fewer strengths characteristics. Instead, it was in the qualitative explanations of their rankings that the nature of a program's culture emerged. Some respondents' explanations reflected a strong degree of integration of strengths in curricula content but not necessarily in the broader environmental aspects of the culture of the program such as through orientations, continuing education or faculty development workshops, and so on. Other respondent comments suggested a mixed level of commitment to integrating strengths in curricula depending on faculty philosophies and interests. Still others noted that strengths are present in written materials, but 
expressed some uncertainty as to whether or not what is espoused actually "plays out consistently" in teaching.

Also in the explanations of rankings, respondents shared the challenges of integrating strengths-based content in their programs. Some of the challenges expressed by survey respondents included faculty views that strengths-based methods were not empirically tested and therefore did not meet the criteria for evidence-based practice. One respondent wrote there is "no evidence to support its usage." Others saw strengths as a perspective not a theoretical construct so they "include it as a basic consideration of enhancing client strengths and empowerment" but not a conceptual framework with its own practice models. Several respondents discussed the challenge of different faculty views on or ambivalence about integrating strengths content. One respondent wrote that it was "not easy to change orientation of faculty; evidence of [its] effectiveness is not clear to some." Another respondent wrote "Not sure how strongly SB content is implemented; Most faculty are modest advocates. Not necessarily a core feature, wish I knew more.” These challenges suggest that a strengths orientation may be an espoused value of their culture, but that they still lack a fully internalized culture of strength in which underlying assumptions of strengths become an unconscious "given" that is fully accepted by the group.

\section{DISCUSSION OF LIMITATIONS AND IMPLICATIONS FOR SOCIAL WORK EDUCATION AND RESEARCH}

This study proffers a modest preliminary glimpse into the progress of social work education toward integrating strengths into MSW programs across the U.S. It is the first study to explore the state of strengths-based social work education since the publication of the first edition of The Strengths Perspective in Social Work Practice (Saleebey, 1992) over 15 years ago. However, the study was compromised by its most obvious limitation, a response rate of only 25\% of U.S. MSW programs; only 44 out of 181 programs responded to the survey. Another limitation is the self reported nature of the data. Consequently, these preliminary findings need to be enhanced through qualitative methods that include content analyzing syllabi, in-depth interviews with multiple levels of stakeholders within select MSW programs. Incorporating these methods will provide more depth and richness to the narrative of strengths that both defines a developing culture of strengths and obscures the remaining presence of deficit and disease still associated with the culture of MSW programs.

Despite its limitations, the study provides some insights about the current state of affairs of strengths-based practice in MSW education. Given the CSWE EPAS standards and the growing awareness and attention strengths-based practice is gaining in the profession, it is understandable that few responding representatives ranked themselves as low (1-3) on infusion of strengths-base content throughout their curricula (2/44) and low on promotion of strengths-based practice methods (1/44). In fact, more than half ranked themselves with scores of 8 to 10 on infusion (23/44) and on promoting strengths-based practice (24/44). Similarly, it is not surprising that program mission, goals, objectives, and readings were the most common characteristics selected to show how programs 
incorporate strengths-based content, since these are subject to review during the CSWE accreditation and reaffirmation processes.

However, it is significant that there are some social work programs that appear to be giving considerable attention to the integration of strengths-based methods. These programs appear to be looking beyond these obvious aspects of their curricula towards the creation of a broader culture of strengths. This was seen in their incorporation of strengths into their relationships with various networks of faculty, staff, students, and field agencies. Further, for these programs that are highly attentive to strengths, the culture of strengths is extended into written program materials and presented at orientation. It is reinforced through faculty development workshops and reified in participatory research methods that include consumers and families as full partners. It is these programs that should be a focus of further research to determine how and why they have gone beyond what will satisfy the mandates of CSWE.

The challenges to the development of a culture of strengths that were raised by a number of respondents suggest new areas of social work education and research. For example, some respondents expressed a suspicion of strengths-based practice methods as conceptually weak and empirically invalid methods for engaging with people and communities in need. Rapp, Saleebey and Sullivan (2005) have identified a number of empirical research studies showing the promise of strengths-based approaches in case management, community development, and clinical practice. While applauding these efforts, they also note that much of that research has methodological flaws that limit their conclusiveness. Consequently, more empirical research demonstrating the comparative effectiveness of strengths-based methods is needed to help strengths-based approaches to practice gain acceptance as legitimate interventions with individuals, families, and communities. Furthermore, educators teaching in the macro areas, e.g., social policy, community practice, and organizational practice are challenged to identify, research, and teach practice models whose underlying assumptions emphasize and build on the strengths of the target system such as asset-based community development (Kretzman \& McKnight, 1993), participatory methods (Castelloe \& Gamble, 2005), and strengthsbased policy analysis (Chapin, 1995).

Especially because of the richness of the qualitative responses, future research should employ qualitative approaches rather than attempting further surveys with a more representative sample of all MSW programs. This form of research would use in-depth interviews with faculty, staff, and students of programs that are moving beyond the surface-level artifacts of a culture of strengths to explore the presence, depth, and breadth of the espoused values and fully incorporated underlying assumptions of a culture of strengths. Social work education has responded to the call for a new paradigm, but curriculum and the profession itself has a way to go to fully actualize a culture of strengths. 


\section{References}

Berg, I. (1994). Family-based services: A solution-focused approach. New York: W.W. Norton \& Company.

Brun, C., \& Rapp, R. (2001). Strengths-based case management: Individuals' perspectives on strengths and the case manager relationship. Social Work, 46(3), 278288.

Butler, A. (2005). A strengths approach to building futures: UK students and refugees together. Community Development Journal, 40(2), 147-157.

Castelloe, P., \& Gamble, D. (2005). Participatory methods in community practice. In M. Weil (Ed.), The handbook of community practice (pp. 261-273). Thousand Oaks, CA: Sage Publications.

Chapin, R. (1995). Social policy development: The strengths perspective. Social Work, 40(4), 506-519.

Chapin, R. (2007). Social policy for effective practice: A strengths approach. New York: McGraw-Hill.

Council on Social Work Education. (2001). Educational policy and accreditation standards. Alexandria, VA: Author.

DeJong, P., \& Berg, I. (2002). Interviewing for solutions ( $2^{\text {nd }}$ ed.). New York: Brooks/Cole Publishing Co.

DeJong, P., \& Miller, S. D. (1995). How to interview for client strengths. Social Work 40(6), 729-736.

DuBois, B., \& Miley, K. (2005). Social work: An empowering profession. Boston: Allyn \& Bacon.

Fisher, R. (2005). History, context, and emerging issues for community practice. In M. Weil (Ed.), The handbook of community practice (pp. 34-58). Thousand Oaks, CA: Sage Publications.

Flexner, A. (2001). Is social work a profession? Research on Social Work Practice, 11(2), 151-165. (originally published in 1915).

Freedman, J., \& Combs, G. (1996). Narrative therapy: The social construction of preferred realities. New York: W.W. Norton \& Co.

Freire, P. (1993). Pedagogy of the oppressed. New York: Continuum Publishing Co.

Green, B. L., McAllister, C. L., \& Tarte, J. M. (2004). The strengths-based practices inventory: a tool for measuring strengths-based service delivery in early childhood and family support programs. Families in Society, 85(4), 326-334.

Helton, L., \& Smith, M. (2004). Mental health practice with children and youth: A strengths and well-being model. New York: Haworth Press. 
Hemelgarn, A., Glisson, C., \& James, L. (2006). Organizational culture and climate: Implications for services and interventions research. Clinical Psychology: Science and Practice, 13(1), 73-89.

Kretzman, J., \& McKnight, J. (1993). Building communities from the inside out. Chicago: ACTA Publications.

Long, D., Tice, C., \& Morrison, J. (2005). Macro social work practice: A strengths perspective. Belmont, CA: Brooks Cole.

Nichols-Casebolt, A., Figueira-Mcdonough, J., \& Netting, E. (2000). Change strategies for integrating women's knowledge into social work curricula. Journal of Social Work Education, 36(1), 65-78.

Poulin, J. (2004). Strengths-based generalist practice: A collaborative approach ( $2^{\text {nd }} \mathrm{ed}$.). Belmont, CA: Brooks/Cole.

Rapp, C. (1998). The strengths model: Case management with people suffering from severe and persistent mental illness. New York: Oxford University Press.

Rapp, C., \& Goscha, R. (2006). The strengths model: Case management with people with psychiatric disabilities ( $2^{\text {nd }}$ ed). New York: Oxford University Press.

Rapp, C., \& Lane, T. (2009). Implementation of brief strengths-based case management: An evidence-based intervention for improving linkage with care. In D. Saleebey (Ed). The strengths perspective in social work practice ( $5^{\text {th }}$ ed., pp 146-160). Boston: Allyn and Bacon.

Rapp, C., Saleebey, D., \& Sullivan, W. P. (2005). The future of strengths-based social work. Advances in Social Work, 6(1), 79-90.

Saleebey, D. (1992). The strengths perspective in social work practice. Boston, MA: Pearson.

Saleebey, D. (Ed.). (2006). The strengths perspective in social work practice (4 $4^{\text {th }} \mathrm{ed}$.). Boston, MA: Pearson.

Schein, E. (2004). Organizational culture and leadership ( $3^{\text {rd }}$ ed.). San Francisco: JosseyBass.

Shlonsky, A., \& Stern, S. (2007). Reflections on the teaching of evidence-based practice. Research on Social Work Practice, 17(5), 603-611.

Solomon, P. (1992). The efficacy of case management services for severely mentally disabled clients. Community Mental Health Journal, 28(3), 163-180.

Soydan, H. (2007). Improving the teaching of evidence-based practice: Challenges and priorities. Research on Social Work Practice, 17(5), 612-618.

Specht, H., \& Courtney, M. (1994). Unfaithful angels. New York: Simon \& Schuster. 
Springer, D. (2007). The teaching of evidence-based practice in social work higher education: Living by the Charlie Parker dictum. Research on Social Work Practice, 17(5), 619-624.

Staudt, M., Howard, M., \& Drake, B. (2001). The operationalization, implementation, and effectiveness of the strengths perspective: A review of empirical studies. Journal of Social Service Research, 27(3), 1-21.

Timberlake, E., Farber, M., \& Sabatino, C. (2008). Generalist social work practice: A strengths-based problem solving approach ( $5^{\text {th }}$ ed.). Boston: Allyn and Bacon.

Waites, C. (2009). Building on strengths: Intergenerational practice with African American families. Social Work, 54(3), 278-287.

Weick, A. (1983). Issues in overturning a medical model of social work practice. Social Work, 28(6), 467-471.

Weick, A., Rapp, C., Sullivan, W., \& Kisthardt, W. (1989). A strengths perspective for social work practice. Social Work, 34(4), 350-354.

\section{Author's note:}

Address correspondence to: Linda Plitt Donaldson, Ph.D., Catholic University of America, 620 Michigan Ave., NE, Washington, DC 20064. Email:

donaldson@cua.edu. 


\section{APPENDIX}

\section{Survey Exploring Strengths-based Content in MSW Programs}

Strengths-based Nature of MSW Program

1. Strengths-based social work practice has been part of the social work lexicon since the first publication of Saleebey's important work in 1992. Some of the words faculty and departments use to connote strengths include, capacities, assets, resources, resilience, etc.

List some of the words that are included in your written materials to indicate the presence of strengths-based social work practice content in your curriculum.

2. The following is a list of characteristics that show how MSW programs incorporate strengths-based content into their curricula. Please click all items that have applied to your MSW program in the last academic year.

Explicitly refer to strengths/capacities/assets in program mission Explicitly refer to strengths/capacities/assets in program goals Explicitly refer to strengths/capacities/assets in program objectives Require texts/articles in foundation year courses that teach methods using strengths and assets as part of the intervention

Offer one or more advanced year concentrations with strengths/assets as the organizing principle, e.g., family preservation Introduce strengths-based concepts as part of program orientation

L Link students to field agencies whose primary method of practice is strengthsbased

Offer faculty development workshops to both part-time and full-time faculty on strengths-based practice content

Offer continuing education in strengths-based methods

Offer one or more discrete courses in strengths-based approaches to social work practice

3. Please list anything else that demonstrates the strengths-based nature of your program.

4a. To what extent does your MSW program infuse strengths-based content throughout the curriculum?

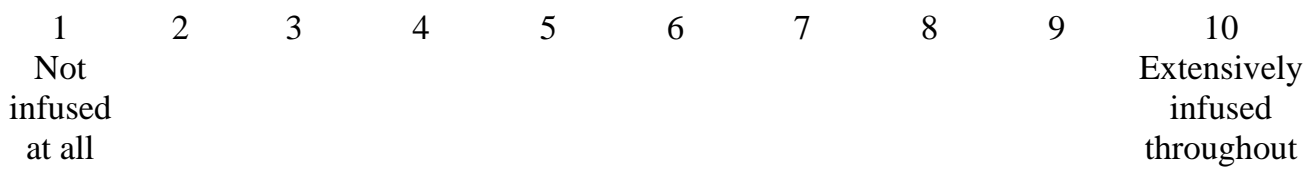

4b. Please elaborate on why you selected this numerical score. 
5a. Overall, how well does your MSW program promote the learning of micro-mezzo-macro strengths-based practice methods?

$\begin{array}{ccccccccccc}1 & 2 & 3 & 4 & 5 & 6 & 7 & 8 & 9 & 10 \\ \text { Not } & & & & & & & & & \begin{array}{c}\text { Extremely } \\ \text { well }\end{array} \\ \text { well } & & & & & & & & & & \end{array}$

5b. Please elaborate on why you selected this numerical score.

6. Whom may we contact if we want to learn more about the strengths-based nature of your MSW program?

MSW Program Demographics

7. What is your position in the department?
Program Chair
Faculty
Staff
Other (please specify)

If you selected other, please specify:

8. How many years have you been with this program?
$0-3$
4-7
$8-12$
$13-18$
19-30
Over 30

9. Approximately how many full-time tenure-line faculty members teach in the MSW program?

0-3 4-7 8-12 13-18 19-30 31-50 51 or more Don't know

10. Approximately how many part-time and/or non tenure-line faculty members teach in the MSW program?
$0-3$
4-7 8-12
13-18
19-30
$31-50$
51 or more
Don’t know

11. How many MSW students are in your program?
0-50 $\quad 51-100 \quad 101-150$
$151-200$
$201-250$
Over 250
Don’t know

12. Please list the concentrations of your MSW program (e.g., advanced generalist, health/mental health, child welfare). 